\title{
Growth of Mycobacterium avium subsp. paratuberculosis, Escherichia coli, and Salmonella Enteritidis during Preparation and Storage of Yogurt
}

\author{
K. Cirone, ${ }^{1,2}$ Y. Huberman, ${ }^{1}$ C. Morsella, ${ }^{1}$ L. Méndez, ${ }^{1}$ M. Jorge, ${ }^{3}$ and F. Paolicchi ${ }^{1,2}$ \\ ${ }^{1}$ Laboratorio de Bacteriología, Grupo Sanidad Animal, EEA INTA, 7620 Balcarce, Argentina \\ ${ }^{2}$ Facultad Ciencias Agrarias, UNMdP, CC 276, 7620 Balcarce, Argentina \\ ${ }^{3}$ Facultad Ciencias Veterinarias, UNCPBA, Campus Universitario, Paraje Arroyo Seco, 7000 Tandil, Argentina \\ Correspondence should be addressed to K. Cirone; kcirone@balcarce.inta.gov.ar
}

Received 19 September 2013; Accepted 20 October 2013

Academic Editors: G. Blaiotta, R. E. Levin, J. L. McKillip, and G. Suzzi

Copyright (C) 2013 K. Cirone et al. This is an open access article distributed under the Creative Commons Attribution License, which permits unrestricted use, distribution, and reproduction in any medium, provided the original work is properly cited.

\begin{abstract}
The purpose of this study was to determine the viability of Mycobacterium avium subsp. paratuberculosis (MAP), Escherichia coli (E. coli), and Salmonella Enteritidis (S. Enteritidis) during preparation and refrigerated storage of yogurt. Three yogurts were prepared using pasteurized commercial milk. Each yogurt was artificially contaminated with (1) MAP, (2) E. coli + S. Enteritidis, and (3) $\mathrm{MAP}+$ E. coli + S. Enteritidis. Samples were taken during and after the fermentation process until day 20 after inoculation. MAP was not detected during their preparation and short-term storage but was recuperated after starting at 180 min after inoculation storage. Live bacterial counts of E. coli, and $S$. Enteritidis increased during the first 24 hours, followed by a slight decrease towards the end of the study. In this study it was shown how MAP, E. coli, and S. Enteritidis resisted the acidic conditions generated during the preparation of yogurt and low storage temperatures. This work contributes to current knowledge regarding survival of MAP, $E$. coli, and $S$. Enteritidis during preparation and refrigerated storage of yogurt and emphasizes the need to improve hygiene measures to ensure the absence of these pathogenic microorganisms in dairy products.
\end{abstract}

\section{Introduction}

Mycobacterium avium subsp. paratuberculosis (MAP) is the causative agent of paratuberculosis or Johne's disease. MAP affects domestic and wild animals and, in cows, causes chronic enteritis, diarrhea, weight loss, and progressive emaciation that can eventually lead to death [1]. MAP has also been linked to human Crohn's disease, a systemic disorder that causes mainly a chronic inflammation of the intestine [2]. It is suggested that humans might be infected through contaminated milk, although relatively little is known about MAP survival during industrial milk manipulation. Some authors have suggested that pasteurization is capable of destroying mycobacteria. Thus, laboratory assays were performed to evaluate MAP heat resistance according to differential distribution of heat treatment during pasteurization [3-6]. In contrast, other authors support the theory that MAP is able to resist pasteurization when it is present in raw milk [7-13].

Viable MAP was detected in commercial pasteurized milk in the UK, the USA, the Czech Republic, and India [10, 11, 1416]. Furthermore, in the Czech Republic, using F-57 or IS 900 real-time PCR, MAP was detected in $49 \%$ of samples of powdered infant milk, with one study yielding viable MAP [17].

Nevertheless, little was published regarding MAP in dairy products other than liquid of powdered milk and some cheese. In general, fermented milk products provide significant barriers to pathogen's growth, starting with heat treatment during pasteurization, followed by the addition of a starter culture and the acidity environment during fermentation as well as refrigerated storage. van Brandt et al. inoculated MAP into ultrahigh temperature (UHT) milk and observed that initial MAP counts, during yogurt fermentation followed by storage at $6^{\circ} \mathrm{C}$, remained unchanged for over 
6 weeks, regardless of the starter culture that was used or the fat content of milk [18].

It is unknown whether the treatment to which milk is subjected to prepare yogurt is sufficient to inactivate viable MAP. Although there are some studies on the behavior of pathogenic bacteria such as Escherichia coli (E. coli) and Listeria monocytogenes during the processing of yogurt, they are affected by different temperatures and low pH. E. coli is an important foodborne pathogen and dairy products may contain these bacteria, normally due to postpasteurization contamination. E. coli O157:H7, the most studied bacterium of the Enterobacteriaceae family, is able to survive the acidic conditions during yogurt preparation and thus causes bacterial enteric infections to the consumers. Massa et al. [19] found that $E$. coli O157:H7 survived fermentation conditions of low $\mathrm{pH}$ levels of 4.5 and at temperatures of $42^{\circ} \mathrm{C}$ up to 5 h. Bachrouri et al. [20] found that E. coli O157:H7 can grow during the preparation of yogurt and survive for 1021 days at different refrigerated storage temperatures. Several studies have shown that the addition of probiotic cultures in yogurt shortens the survival of L. monocytogenes and $E$. coli O157:H7 during the storage period [21-24]. However, not much literature is available about similar studies using Salmonella Enteritidis (S. Enteritidis).

The aim of this study was to find out the viability of MAP, E. coli, and S. Enteritidis during the traditional processing and refrigerated storage of yogurt made from milk after experimental inoculation and determine if there are synergistic or antagonistic effects between these bacteria.

\section{Materials and Methods}

2.1. Bacteria Strains. Bacterial strains were isolated at the bacteriology laboratory of the National Institute of Agricultural Technology (INTA), Balcarce (Argentina), using MAP strain INTA SB, isolated from a commercial milk, E. coli strain INTA 116/C3, obtained from bovine feces, and $S$. Enteritidis strain INTA 86/360, isolated from poultry.

2.2. Inoculums Preparation. For the preparation of the inocula, the aforementioned strains were thawed from liquid nitrogen. MAP was cultured onto solid Herrold's egg yolk medium (HEYM) plus $0.0002 \%$ (wt/vol) mycobactin J (Allied Monitor Inc., Fayette, MO, USA) and sodium pyruvate (Sigma Chemical Co., St. Louis, MO, USA) for 8 weeks at $37^{\circ} \mathrm{C}$. For the preparation of the inoculum, few colonies were suspended in $15 \mathrm{~mL}$ of phosphate buffered saline (PBS) $(\mathrm{pH}$ = 7), adjusted to turbidity of 0.5 in McFarland scale [25] containing $1.5 \times 10^{8}$ colony forming units $(\mathrm{CFU}) \cdot \mathrm{mL}^{-1}$. E. coli was grown onto McConkey (MC) agar and $S$. Enteritidis was cultured onto Xilosa-Lisina-Desoxicolato agar with the addition of $0.46 \%$ of Tergitol-4 (Sigma Chemical Co., St. Louis, MO, USA) (XLDT4). Both MC and XLDT4 agars were incubated overnight at $37^{\circ} \mathrm{C}$. Afterwards, one colony of either E. coli or S. Enteritidis was suspended in PBS pH 7.2 and used to seed brain-heart infusion (BHI) broth (Oxoid, UK), which were further incubated overnight at $37^{\circ} \mathrm{C}$. For the preparation of the inocula both $\mathrm{BHI}$ tubes were diluted with
PBS $(\mathrm{pH}=7.2)$ to a final concentration of $1.5 \times 10^{8}$ colony forming units $(\mathrm{CFU}) \cdot \mathrm{mL}^{-1}$.

2.3. Preparation of Yogurt. Three traditional yogurts were prepared using $360 \mathrm{~mL}$ of commercial UHT milk, $125 \mathrm{~g}$ of commercial yogurt containing starter culture of Streptococcus thermophilus and Lactobacillus bulgaricus, and $5 \mathrm{~mL}$ of the corresponding bacterial inoculum: Yogurt 1(Y1): MAP, Yogurt 2 (Y2): E. coli + S. Enteritidis, and Yogurt 3 (Y3): MAP + E. coli $+S$. Enteritidis. The fermentation was carried out in a thermostatic orbital shaker (New Brunswick Scientific, Model E24) at $43^{\circ} \mathrm{C}$ for $3 \mathrm{~h}$. Afterwards, the yogurts were stored at $4^{\circ} \mathrm{C}$ for 20 days.

2.4. Samples of Yogurt. Samples of $50 \mathrm{~mL}$ were taken out before and throughout the preparation time at $20 \mathrm{~min}$, $45 \mathrm{~min}, 65 \mathrm{~min}, 90 \mathrm{~min}, 115 \mathrm{~min}, 135 \mathrm{~min}, 155 \mathrm{~min}, 180 \mathrm{~min}$, and $270 \mathrm{~min}$. Furthermore, samples were also taken during storage at $4.5 \mathrm{~h}, 24 \mathrm{~h}, 48 \mathrm{~h}, 4$ days, 10 days, 15 days, and 20 days after inoculation.

\subsection{Live Bacterial Counts}

$M A P$. For decontamination of the samples the method proposed by Tacquet et al. [26] was used with some modifications: $35 \mathrm{~mL}$ of each yogurt was centrifuged at $6000 \mathrm{rpm}$ for $20 \mathrm{~min}$ in a refrigerated centrifuge (Sigma 16-K, Germany) and the pellet was resuspended in $15 \mathrm{~mL}$ of oxalic acid at $5 \%$ (wt/vol). The samples were kept at $37^{\circ} \mathrm{C}$ for $10 \mathrm{~min}$ and then centrifuged once more. Afterwards, the pellet was resuspended in $2 \mathrm{~mL}$ PBS and finally $160 \mu \mathrm{L}$ was cultured in HEYM plus vancomycin $0.01 \%$ (wt/vol), amphotericin B $5 \%(\mathrm{wt} / \mathrm{vol})$, nalidixic acid $0.3 \%$ (wt/vol), and nystatin $0.01 \%$ (wt/vol). The medium was incubated at $37^{\circ} \mathrm{C}$ for 40 days and was weekly observed for MAP growth. The final CFU was calculated taking into account that each slant was inoculated with $160 \mu \mathrm{L}$. The results are expressed as $\mathrm{CFU} \cdot \mathrm{mL}^{-1}$ of yogurt.

E. coli and S. Enteritidis. $5 \mathrm{~mL}$ was taken from each yogurt sample and 10 decimal logarithmic dilutions were made in PBS ( $\mathrm{pH}=7.2$ ). Using the Miles and Misra method [27], an aliquot of $20 \mu \mathrm{L}$ from each dilution was plated onto triplicate MC and XLDT4 for E. coli and S. Enteritidis strains, respectively. The agar plates were incubated overnight at $37^{\circ} \mathrm{C}$ and afterwards colonies were counted in the dilution that permitted the identification of 3-30 separate colonies. The results were expressed as $\mathrm{CFU} \cdot \mathrm{mL}^{-1}$ of yogurt.

2.6. $\mathrm{pH}$ Determination. $\mathrm{pH}$ was measured using a $\mathrm{pH}$ meter (Schott Gerate, CG 820, USA).

2.7. Statistical Analysis. The linear regression curves of log counts were analyzed versus time of preparation and storage. The analysis was performed only for E. coli and S. Enteritidis by comparing the behavior of both bacteria in the yogurt and of each in the two yogurt bacteria which were inoculated. The program Statistical Analysis Software (SAS) was used [28]. 


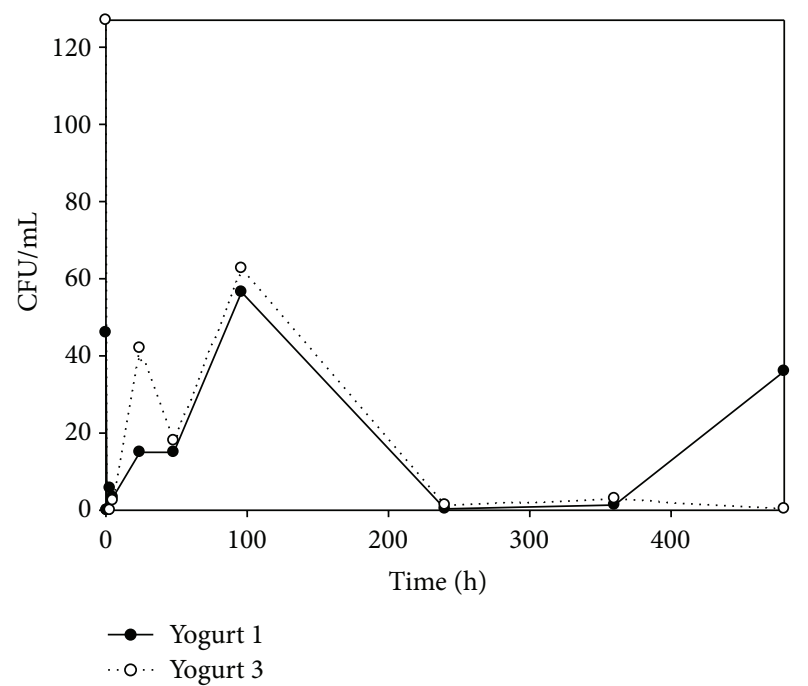

FIGURE 1: CFU/mL of MAP during preparation and refrigerated storage of yogurts $\mathrm{Y} 1$ and $\mathrm{Y} 3$.

\section{Results}

3.1. MAP Counts. At the beginning of the preparation process, counts of MAP in $Y 1$ and $Y 3$ were 46 and $127 \mathrm{CFU} \cdot \mathrm{mL}^{-1}$, respectively. During the preparation process (up to $135 \mathrm{~min}$ ) MAP was not detected in any of the yogurts. After that, MAP counts in $Y 1$ were $5.6 \mathrm{CFU} \cdot \mathrm{mL}^{-1}$ at $180 \mathrm{~min}$, but MAP was not isolated from $Y 3$. After $4.5 \mathrm{~h}$ and during the storage at $4^{\circ} \mathrm{C}$, the $\mathrm{CFU} \cdot \mathrm{mL}^{-1}$ increased and reached a maximum of 56,5 and $62,7 \mathrm{CFU} \cdot \mathrm{mL}^{-1}$ at 4 days in both yogurts, after which the viability began to fall again (Figures 1 and 2).

3.2. E. coli and S. Enteritidis Counts. The initial counts for $E$. coli and $S$. Enteritidis were 5.3 and $5.5 \log$ of $\mathrm{CFU} \cdot \mathrm{mL}^{-1}$ and decreased during the first hour of preparation. Both bacteria reached their maximum counts at $24 \mathrm{~h}\left(6.4 \log\right.$ of $\mathrm{CFU} \cdot \mathrm{mL}^{-1}$ for E. coli and $5.3 \mathrm{log}$ of $\mathrm{CFU} \cdot \mathrm{mL}^{-1}$ for $S$. Enteritidis). The viability of both bacteria continued to slightly decline until the end of the trial ( $5 \log$ for E. coli and $4.6 \log$ for $S$. Enteritidis) (Figures 3, 4, 5, and 6).

3.3. $p H$. The initial $\mathrm{pH}$ was 6.1 for the three yogurts. During the fermentation process, the $\mathrm{pH}$ gradually decreased to 4.5. From $180 \mathrm{~min}$ to $4.5 \mathrm{~h}$, values remained in that range. Afterwards, the $\mathrm{pH}$ remained stable at 4.5 throughout storage until the end of the trial (Figures 7 and 8).

3.4. Statistical Analysis. The regression analysis of the log counts of E. coli and $S$. Enteritidis versus the preparation and storage time in $Y 3$ gave an $R^{2}$ of $0.94(P<0.05)$, which shows that the variation in the preparation of storage time is the cause of $94.25 \%$ of the variation in the bacterial counts. By comparing the behavior of both bacteria, statistical differences were observed $(P<0.05)$. In $Y 2$, the $R^{2}$ was 0.58 indicating that the variation in the preparation and storage time explained $58.27 \%$ of the variation in the bacterial

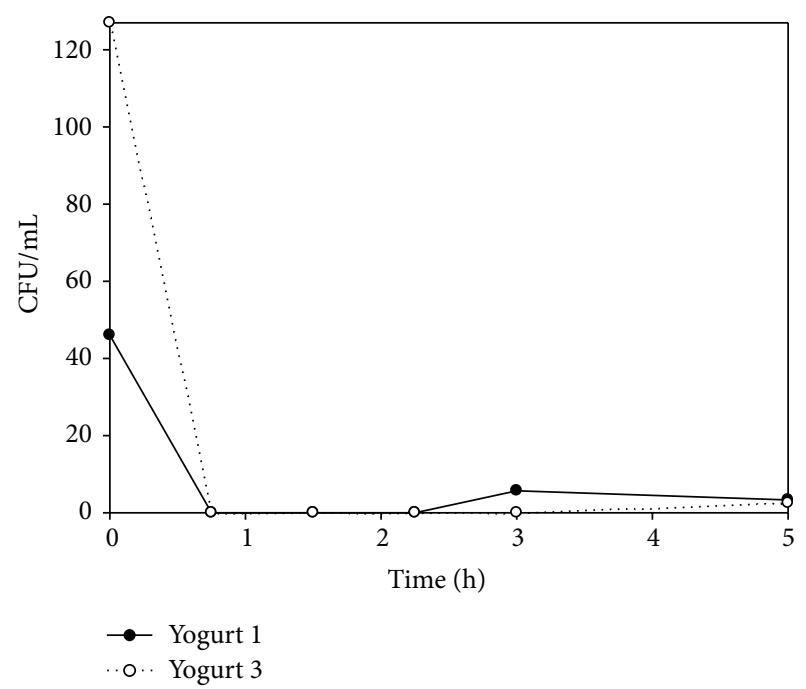

FIGURE 2: CFU/mL of MAP during the preparation of yogurts Y1 and $\mathrm{Y3}$.

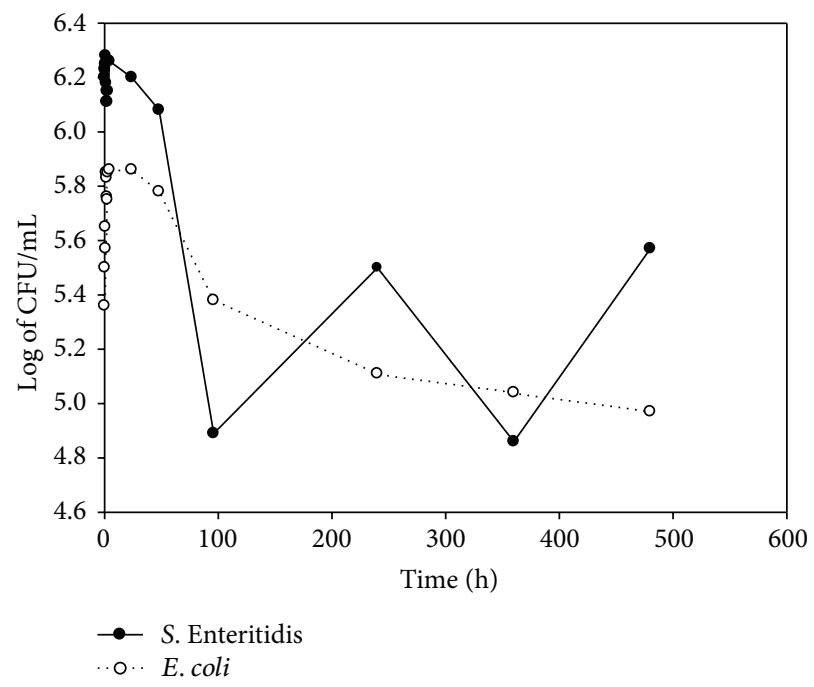

FIGURE 3: Log of CFU/mL of E. coli and S. Enteritidis during yogurt preparation and refrigerated storage in $\mathrm{Y} 3$.

counts. In this case, the behaviors of both bacteria were not statistically different $(P>0.05)$. On the other hand, the behavior analysis of $E$. coli in $Y 3$ and $Y 2$ showed no significant differences $(P>0.05)$. Instead, $S$. Enteritidis showed a different behavior in both yogurts $(P<0.05)$, which occurs in $Y 3$ inoculated with MAP.

\section{Discussion}

4.1. Growth of MAP. As milk is a nutrient medium suitable for growth of microorganisms, raw milk can be an important source of pathogens for humans. The ability of MAP to survive certain food processing methods and to persist unfavorable conditions, combined with its possible involvement in Crohn's disease, has raised concern with respect to human 


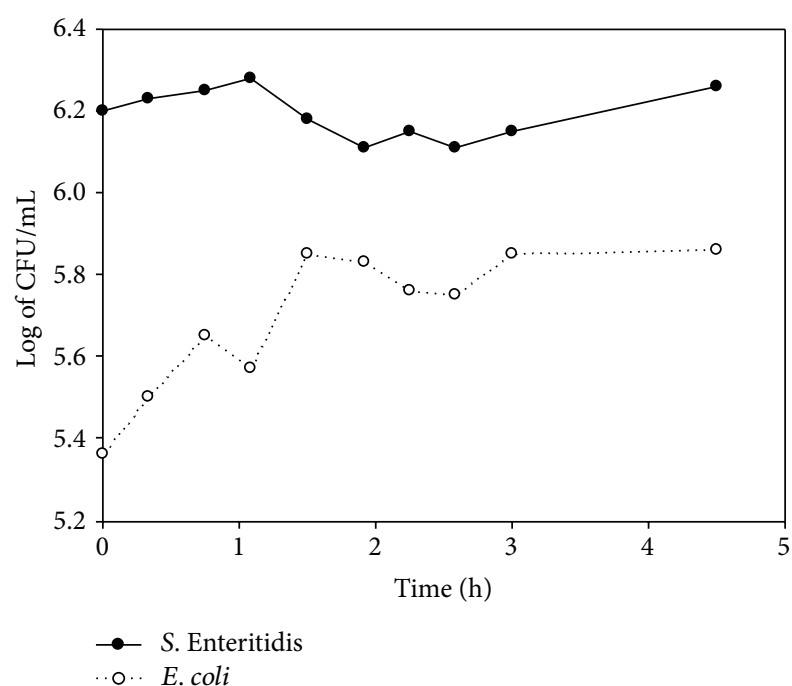

FIGURE 4: Log of CFU/mL of E. coli and S. Enteritidis during yogurt preparation in $\mathrm{Y} 3$.

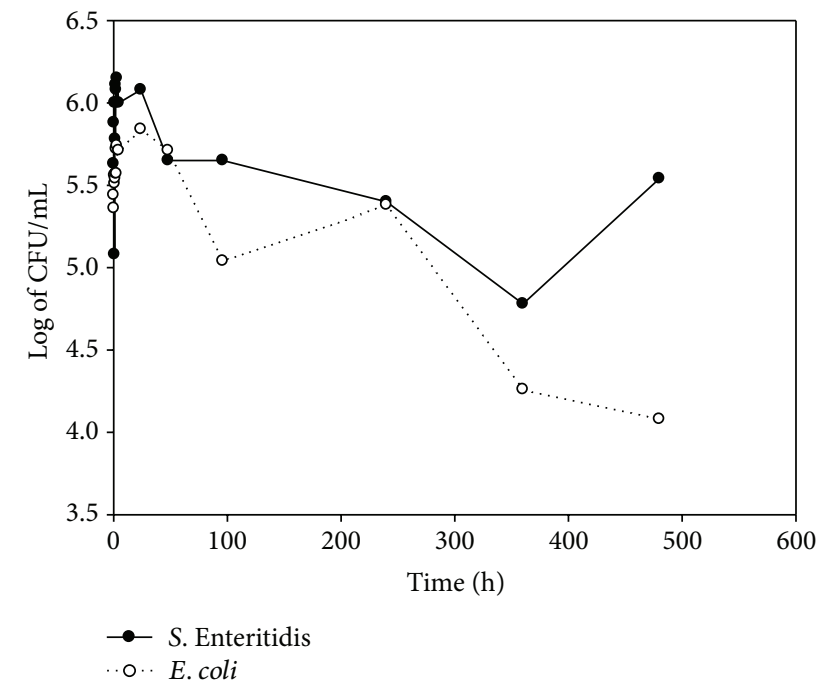

FIGURE 5: Log of CFU/mL of E. coli and S. Enteritidis during yogurt preparation and refrigerated storage in $\mathrm{Y} 2$.

exposure to this pathogen. For the commercial production of yogurt and other fermented milk products, raw milk is usually first pasteurized. However, the complete elimination of MAP by pasteurization is still under debate. If indeed MAP is present in pasteurized milk, it might be transferred to humans upon consumption of by-products. Therefore, it is interesting to gain insights into the behavior of MAP in such products as the acidic nature of yogurt $(\mathrm{pH}$ about 4-4.5) generally contributes to the inactivation of bacterial pathogens [18].

MAP was isolated until the end of the present study (20 days of storage), showing its capacity to withstand the acidic conditions generated during yogurt preparation and the low temperatures of storage. In all samples, MAP counts were low due to the aggressive step of decontamination.

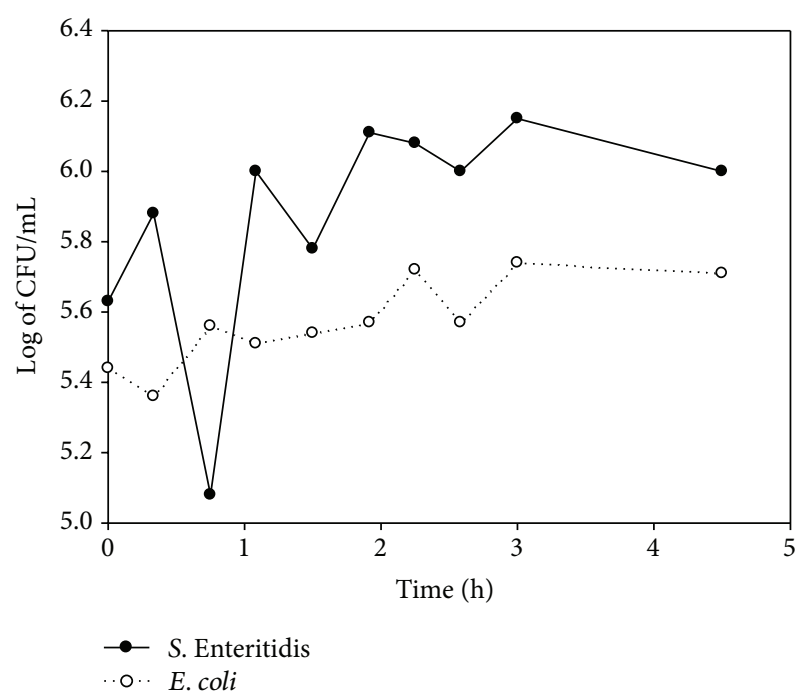

FIGURE 6: Log of CFU/mL of E. coli and S. Enteritidis during yogurt preparation in $\mathrm{Y} 2$.

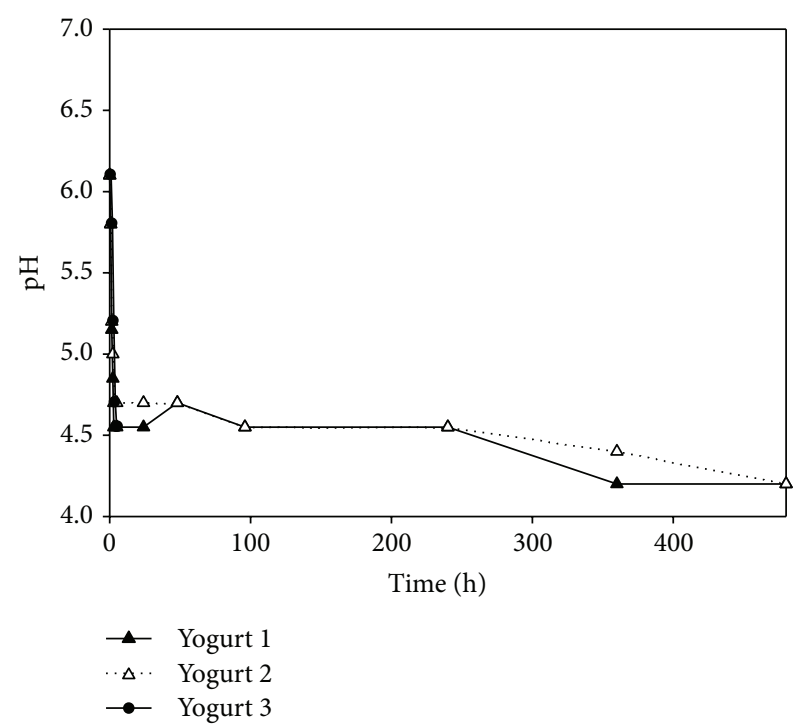

FIGURE 7: pH evolution during yogurt preparation and refrigerated storage in $\mathrm{Y} 1, \mathrm{Y} 2$, and $\mathrm{Y} 3$.

van Brandt et al. [18] found that initial MAP counts remain unchanged over the 6 weeks of refrigerated storage, regardless of starter culture used and the fat content of milk, but did not evaluate its isolation during preparation. Sung and Collins [29] found that at low $\mathrm{pH}$ levels in vitro, MAP expressed two proteins related at the acid tolerance. However, they could not predict MAP survival curve in foods where other factors might affect its viability. In the present work, MAP was not isolated during the preparation process, which suggests that the sudden decrease in $\mathrm{pH}$ might have caused damage to the bacteria and therefore it was impossible to culture it on artificial culture media. Furthermore, MAP was recuperated at $4.5 \mathrm{~h}$ after inoculation suggesting that initially it might have 


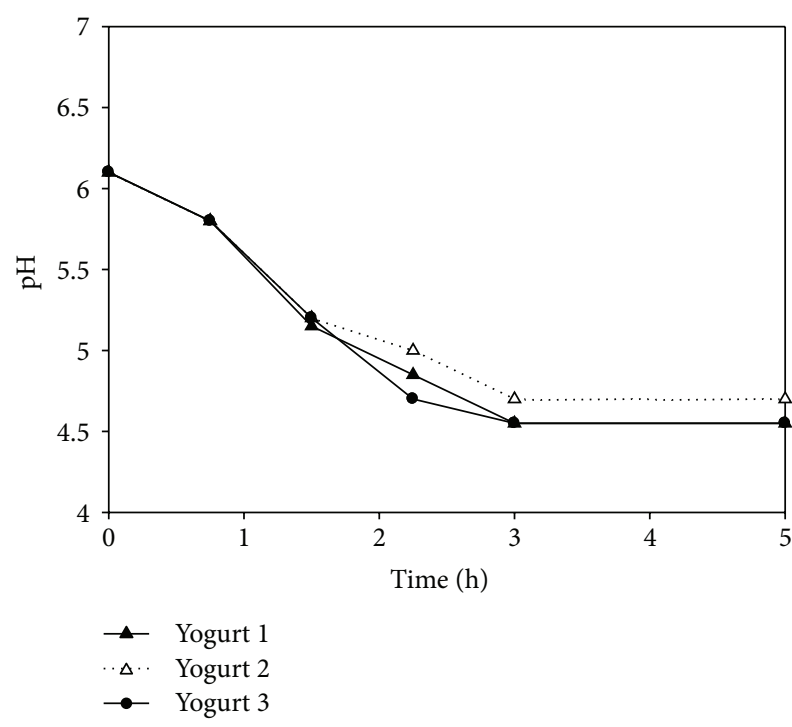

FIGURE 8: pH evolution during yogurt preparation in Y1, Y2, and Y3.

been in a viable noncultivable state and after an adaptation period.

In a previous work, during the preparation and storage of cheese made with caprine and bovine milk, MAP was isolated only when nonpasteurized milk was used up to 60 days of maturation. High values of $\mathrm{pH}$ were observed between 30 and 45 days of storage, coinciding with the further MAP isolation [30]. It has also been observed that $\mathrm{pH}$, temperature, and salt concentrations can affect MAP viability [31-33].

\subsection{Growth of E. coli and S. Enteritidis}

4.2.1. Preparation. To our knowledge, there are no referential studies on the survival of $S$. Enteritidis during the preparation of dairy products like yogurt. However, some studies have focused on E. coli, especially the pathogenic serotype O157:H7, which causes hemolytic uremic syndrome. Bachrouri et al. [20] observed that E. coli O157:H7 counts increased during fermentation, whereas Dineen et al. [22] found that this bacterium was not recovered during yogurt fermentation. Therefore, in this study, high inoculation levels were chosen in order to assure recuperation of both $E$. coli and $S$. Enteritidis at the entire process of production and conservation of the yogurts. Hence, it was demonstrated that $E$. coli counts had decreased slowly, while $S$. Enteritidis maintained stable. These differences may be explained by the fact that in these abovementioned works the fermentation conditions were different: higher fermentation temperature $\left(46-7^{\circ} \mathrm{C}\right)$, longer fermentation time of $24 \mathrm{~h}$, and lower final pH (4.1). Similarly, Soudah et al. [34] observed that E. coli O157:H7 did not survive fermentation in yogurt containing Lactobacillus delbrueckii subsp. bulgaricus and Streptococcus thermophilus at $47^{\circ} \mathrm{C}$. However, other researchers found that E. coli O157:H7 survived the fermentation of yogurt at $42^{\circ} \mathrm{C}$ $[19,23]$. Furthermore, the exposure to acid environments for short times increased the tolerance acid of $E$. coli, thus permitting survival for longer periods [35]. These results are in agreement with those of the present work, where, despite suffering a slight decline, E. coli was recovered during the fermentation process at $43^{\circ} \mathrm{C}$ and a final $\mathrm{pH}$ of 4.7. These results suggest that the conditions of fermentation are important factors that may affect the survival of E. coli.

4.2.2. Storage. Bachrouri et al. [20] observed that viability of E. coli began to decline until 7 days of storage, when no viable bacteria were detected. Barrantes et al. [21] found that no viable E. coli $\mathrm{O} 157: \mathrm{H} 7$ was detected in yogurts made with and without probiotics, at 16 and 28 days of storage, respectively. Govaris et al. [23] did not detect viable E. coli O157:H7 between 5 and 8 days of storage at $4^{\circ} \mathrm{C}$ or between 4 and 6 days of storage at $12^{\circ} \mathrm{C}$ and the $\mathrm{pH}$ of the yogurts was stable. However, in the present work, using a similar inoculation dose in the yogurts, E. coli and S. Enteritidis were isolated at 20 days of cold storage. This reveals the capacity of these bacteria to tolerate acidity conditions when they are present in raw material. On the other hand, lactic bacteria produce compounds such as organic acids, hydrogen peroxide, diacetyl, and bacteriocins, which inhibit the growth of contaminant microflora and pathogens such as Staphylococcus aureus, Clostridium botulinum, and L. monocytogenes [24]. In the present study, it is suggested that the presence of MAP in $Y 3$ contributed to the reduced survival of $S$. Enteritidis in comparison with $Y 2$. However, the mechanism by which these changes occur was not studied. There is also a lack of information about the competitive inhibition of MAP and other bacteria for nutrients in the yogurt during preparation. Nevertheless, if such competition does occur, MAP would be in disadvantage as it is the cultivable mycobacterium with the slowest growth, with a slow generation time of over $20 \mathrm{~h}$, under optimal growth conditions, whereas $S$. Enteritidis has a generation time of 20 minutes [36].

Further studies should be performed to assess the competitive inhibition mechanisms of these pathogens in vitro as well as their resistance to different temperatures and $\mathrm{pH}$ levels in order to improve optimal conditions for the processing of dairy products and to ensure their elimination.

\section{Conclusions}

The present study presents evidence that pathogen bacteria like MAP, E. coli, and S. Enteritidis can survive yogurt fermentation conditions and low $\mathrm{pH}$ levels followed by refrigerated storage for at least 20 days. Thus these pathogens are present in raw materials and they might reach consumers. The importance of implementing good manufacturing practices during the production and storage of yogurt is highlighted. Therefore, similar studies should be carried out with different concentrations of bacteria, in an attempt to simulate natural contamination.

\section{Acknowledgment}

The study was supported by a Project (AESA 202831) of the National Agricultural Technology Institute (INTA) of Argentina. 


\section{References}

[1] K. V. Nordlund, W. J. Goodger, J. Pelletier, and M. T. Collins, "Associations between subclinical paratuberculosis and milk production, milk components, and somatic cell counts in dairy herds," Journal of the American Veterinary Medical Association, vol. 208, no. 11, pp. 1872-1876, 1996.

[2] J. Hermon-Taylor and T. Bull, "Crohn's disease caused by Mycobacterium avium subspecies paratuberculosis: a public health tragedy whose resolution is long overdue," Journal of Medical Microbiology, vol. 51, no. 1, pp. 3-6, 2002.

[3] J. R. Stabel, "On-farm batch pasteurization destroys Mycobacterium paratuberculosis in waste milk," Journal of Dairy Science, vol. 84, no. 2, pp. 524-527, 2001.

[4] L. E. Pearce, H. T. Truong, R. A. Crawford, G. F. Yates, S. Cavaignac, and G. W. De Lisle, "Effect of turbulent-flow pasteurization on survival of Mycobacterium avium subsp. paratuberculosis added to raw milk," Applied and Environmental Microbiology, vol. 67, no. 9, pp. 3964-3969, 2001.

[5] D. Lynch, K. N. Jordan, P. M. Kelly, T. Freyne, and P. M. Murphy, "Heat sensitivity of Mycobacterium avium ssp. paratuberculosis in milk under pilot plant pasteurization conditions," International Journal of Dairy Technology, vol. 60, no. 2, pp. 98-104, 2007.

[6] J. L. W. Rademaker, M. M. M. Vissers, and M. C. Te Giffel, "Effective heat inactivation of Mycobacterium avium subsp. paratuberculosis in raw milk contaminated with naturally infected feces," Applied and Environmental Microbiology, vol. 73, no. 13, pp. 4185-4190, 2007.

[7] I. R. Grant, H. J. Ball, S. D. Neill, and M. T. Rowe, "Inactivation of Mycobacterium paratuberculosis in cows' milk at pasteurization temperatures," Applied and Environmental Microbiology, vol. 62, no. 2, pp. 631-636, 1996.

[8] I. R. Grant, H. J. Ball, and M. T. Rowe, "Effect of higher pasteurization temperatures, and longer holding times at $72^{\circ} \mathrm{C}$, on the inactivation of Mycobacterium paratuberculosis in milk," Letters in Applied Microbiology, vol. 28, no. 6, pp. 461-465, 1999.

[9] I. R. Grant, C. M. Pope, L. M. O’Riordan, H. J. Ball, and M. T. Rowe, "Improved detection of Mycobacterium avium subsp. paratuberculosis in milk by immunomagnetic PCR," Veterinary Microbiology, vol. 77, no. 3-4, pp. 369-378, 2000.

[10] I. Grant, E. Hitchings, H. Ball, and M. Rowe, "Impact of commercial HTST pasteurization on Mycobacterium avium subsp. paratuberculosis in naturally infected cow's milk," Applied and Environmental Microbiology, vol. 68, pp. 602-607, 2002.

[11] I. R. Grant, H. J. Ball, and M. T. Rowe, "Incidence of Mycobacterium paratuberculosis in bulk raw and commercially pasteurized cows' milk from approved dairy processing establishments in the United Kingdom," Applied and Environmental Microbiology, vol. 68, no. 5, pp. 2428-2435, 2002.

[12] I. R. Grant, R. B. Kirk, E. Hitchings, and M. T. Rowe, "Comparative evaluation of the MGIT and BACTEC culture systems for the recovery of Mycobacterium avium subsp. paratuberculosis from milk," Journal of Applied Microbiology, vol. 95, no. 1, pp. 196-201, 2003.

[13] P. Hammer, C. Kiesner, H.-G. Walte, K. Knappstein, and P. Teufel, "Heat resistance of Mycobacterium avium ssp. paratuberculosis in raw milk tested in a pilot plant pasteurizer," Kieler Milchwirtschaftliche Forschungsberichte, vol. 54, no. 4, pp. 275230, 2002.

[14] J. L. E. Ellingson, J. L. Anderson, J. J. Koziczkowski et al., “Detection of viable Mycobacterium avium subsp. paratuberculosis in retail pasteurized whole milk by two culture methods and PCR," Journal of Food Protection, vol. 68, no. 5, pp. 966-972, 2005.

[15] W. Y. Ayele, P. Svastova, P. Roubal, M. Bartos, and I. Pavlik, "Mycobacterium avium subspecies paratuberculosis cultured from locally and commercially pasteurized cow's milk in the Czech Republic," Applied and Environmental Microbiology, vol. 71, no. 3, pp. 1210-1214, 2005.

[16] H. Shankar, S. V. Singh, P. K. Singh, A. V. Singh, J. S. Sohal, and R. J. Greenstein, "Presence, characterization, and genotype profiles of Mycobacterium avium subspecies paratuberculosis from unpasteurized individual and pooled milk, commercial pasteurized milk, and milk products in India by culture, PCR, and PCR-REA methods," International Journal of Infectious Diseases, vol. 14, no. 2, pp. e121-e126, 2010.

[17] K. Hruska, M. Bartos, P. Kralik, and I. Pavlik, "Mycobacterium avium subsp. paratuberculosis in powdered infant milk: paratuberculosis in cattle-The public health problem to be solved," Veterinarni Medicina, vol. 50, no. 8, pp. 327-335, 2005.

[18] L. van Brandt, K. Coudijzer, L. Herman, C. Michiels, M. Hendrickx, and G. Vlaemynck, "Survival of Mycobacterium avium ssp. paratuberculosis in yoghurt and in commercial fermented milk products containing probiotic cultures," Journal of Applied Microbiology, vol. 110, no. 5, pp. 1252-1261, 2011.

[19] S. Massa, C. Altieri, V. Quaranta, and R. de Pace, "Survival of Escherichia coli O157: $\mathrm{H} 7$ in yoghurt during preparation and storage at 4०C," Letters in Applied Microbiology, vol. 24, no. 5, pp. 347-350, 1997.

[20] M. Bachrouri, E. J. Quinto, and M. T. Mora, "Kinetic parameters of Escherichia coli O157:H7 survival during fermentation of milk and refrigeration of home-made yoghurt," International Dairy Journal, vol. 16, no. 5, pp. 474-481, 2006.

[21] X. Barrantes, D. Railey, M. Arias, and C. Chaves, "Evaluación del efecto de cultivos probióticos adicionados a yogurt comercial, sobre poblaciones conocidas de Listeria monocytogenes y Escherichia coli O157:H7," Archivos Latinoamericanos De Nutrición, vol. 54, no. 3, 2004.

[22] S. S. Dineen, K. Takeuchi, J. E. Soudah, and K. J. Boor, "Persistence of Escherichia coli O157:H7 in dairy fermentation systems," Journal of Food Protection, vol. 61, no. 12, pp. 1602-1608, 1998.

[23] A. Govaris, P. Koidis, and K. Papatheodorou, "Behaviour of Escherichia coli O157:H7 in sour milk, cows' milk yogurt and ewes' milk yogurt," Journal of Dairy Research, vol. 69, no. 4, pp. 655-660, 2002.

[24] C. Nettles and S. Barefoot, "Biochemical and genetic characteristics of bacteriocins of food associated lactic acid bacteria," Journal of Food Protection, vol. 56, pp. 338-356, 1993.

[25] R. Cruickshank, J. Duguid, B. Marmion, and R. Swain, Medical Microbiology: The Practice of Medical Microbiology, vol. 2, Churchill Livingstone, New York, NY, USA, 12th edition, 1975.

[26] A. Tacquet, F. Tison, B. Devulder, and P. Roos, "Techniques for decontamination of pathological specimens for culturing mycobacteria," Bulletin of the International Union against Tuberculosis, vol. 39, no. 1, pp. 21-24, 1967.

[27] A. Miles, S. Misra, and J. Irwin, "The estimation of the bactericidal power of the blood," Journal of Hygiene, vol. 38, pp. 732749, 1938.

[28] SAS, Statistical Analysis System. SAS User's Guide: Statistics, SAS Institute, Cary, NC, USA, 1998.

[29] N. Sung and M. T. Collins, "Variation in resistance of Mycobacterium paratuberculosis to acid environments as a function of culture medium," Applied and Environmental Microbiology, vol. 69, no. 11, pp. 6833-6840, 2003. 
[30] K. Cirone, C. Morsella, D. Colombo, and F. Paolicchi, "Viabilidad de Mycobacterium avium subsp. paratuberculosis en quesos elaborados con leche caprina y bovina," Acta Bioquímica Clínica Latinoamericana, vol. 40, pp. 507-513, 2006.

[31] N. Sung and M. T. Collins, "Effect of three factors in cheese production ( $\mathrm{pH}$, salt, and heat) on Mycobacterium avium subsp., paratuberculosis viability," Applied and Environmental Microbiology, vol. 66, no. 4, pp. 1334-1339, 2000.

[32] J. A. Donaghy, N. L. Totton, and M. T. Rowe, "Persistence of Mycobacterium paratuberculosis during manufacture and ripening of cheddar cheese," Applied and Environmental Microbiology, vol. 70, no. 8, pp. 4899-4905, 2004.

[33] U. Spahr and K. Schafroth, "Fate of Mycobacterium avium subsp. paratuberculosis in Swiss hard and semihard cheese manufactured from raw milk," Applied and Environmental Microbiology, vol. 67, no. 9, pp. 4199-4205, 2001.

[34] J. Soudah, K. Boor, and G. Jeffers, “The persistence of Escherichia coli $\mathrm{O} 157: \mathrm{H} 7$ in dairy productos fermented by lactic acid bacteria," Journal of Dairy Science, vol. 79, no. 1, pp. 121-126, 1996.

[35] H. Tosun and S. Aktug Gonul, "The effecto of acid adaptation conditions on acid tolerance response of Escherichia coli O157:H7," Turkish Journal of Biology, vol. 29, pp. 197-102, 2005.

[36] R. S. Lambrecht, J. F. Carriere, and M. T. Collins, "A model for analyzing growth kinetics of a slowly growing Mycobacterium sp.", Applied and Environmental Microbiology, vol. 54, no. 4, pp. 910-916, 1988. 

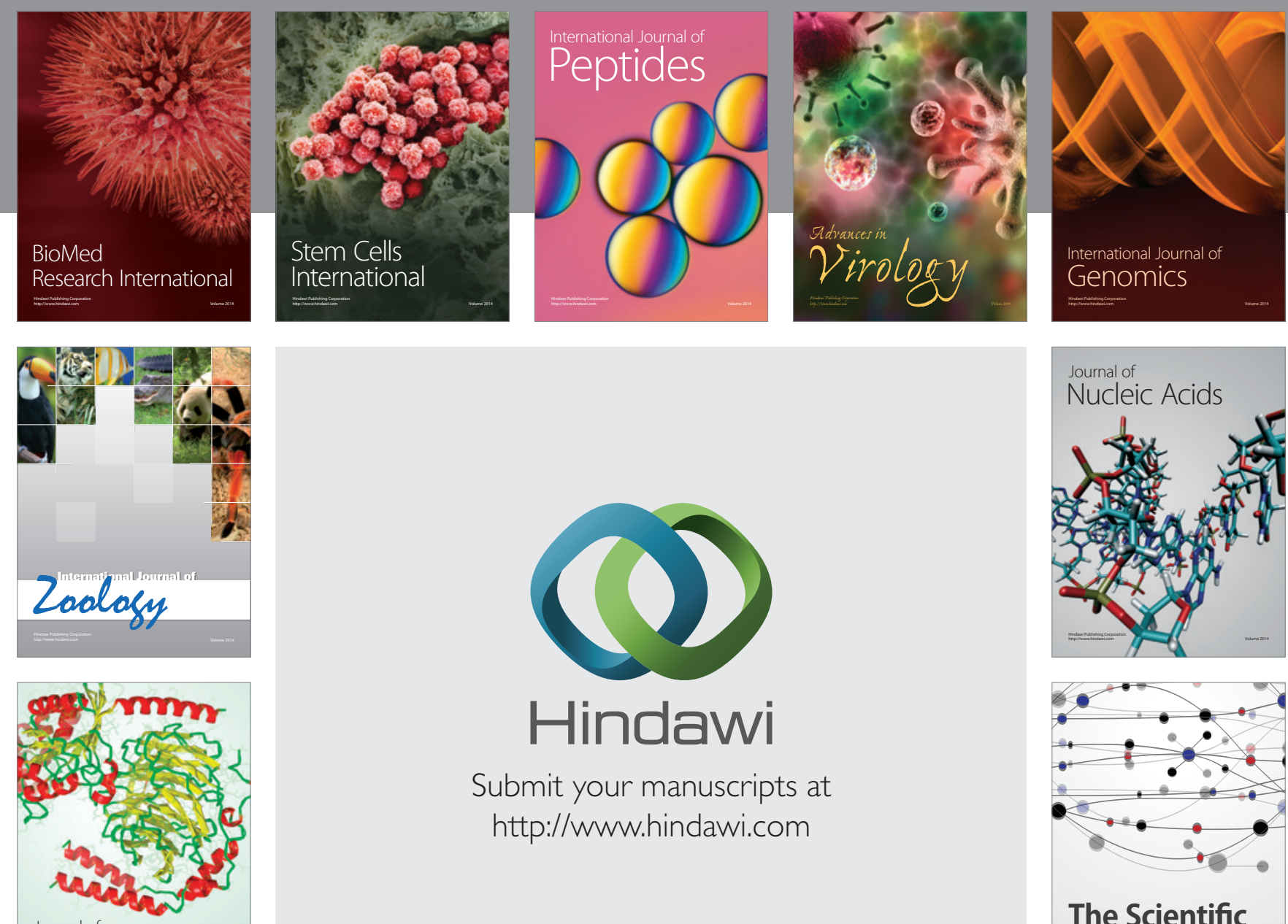

Submit your manuscripts at

http://www.hindawi.com

Journal of
Signal Transduction
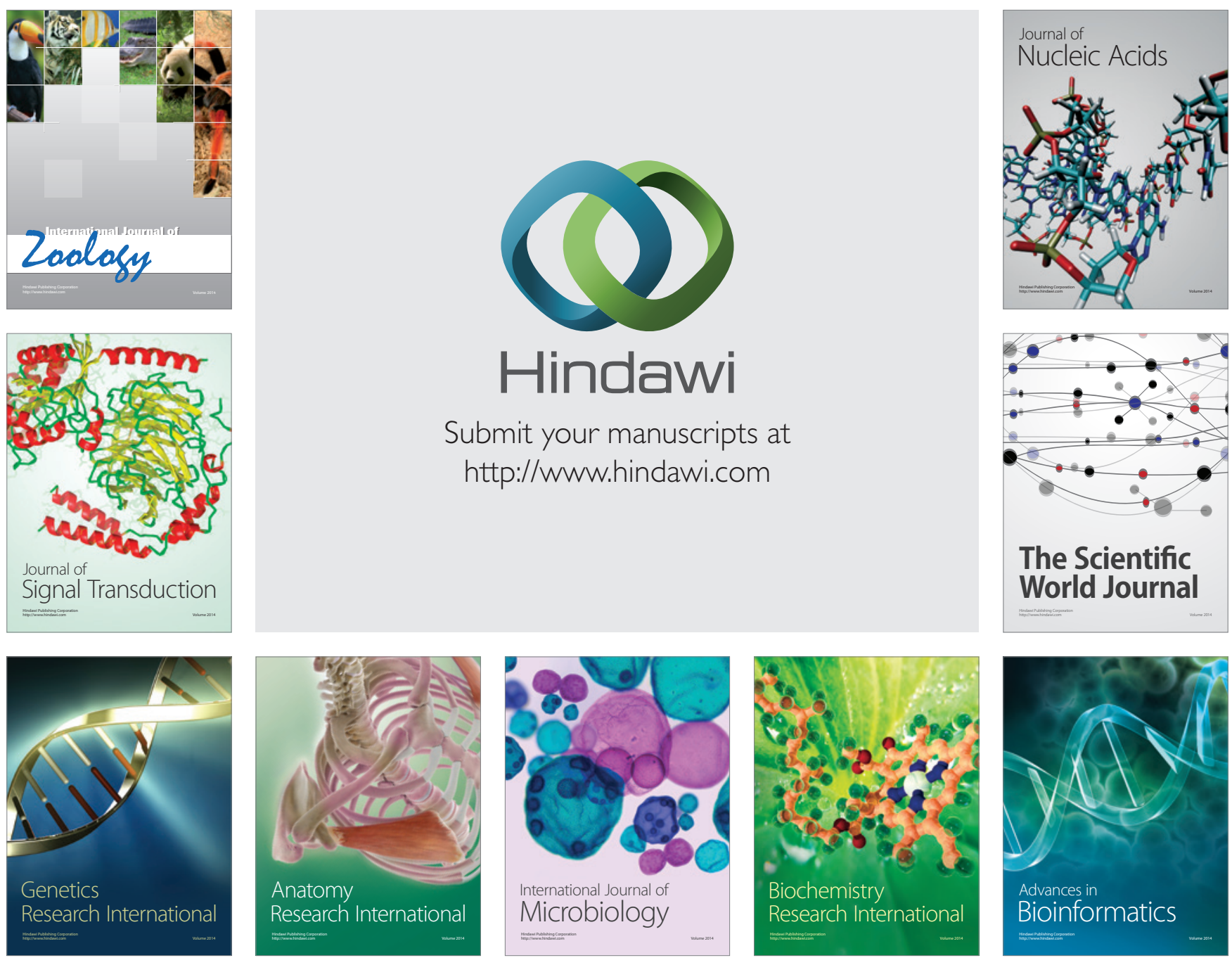

The Scientific World Journal
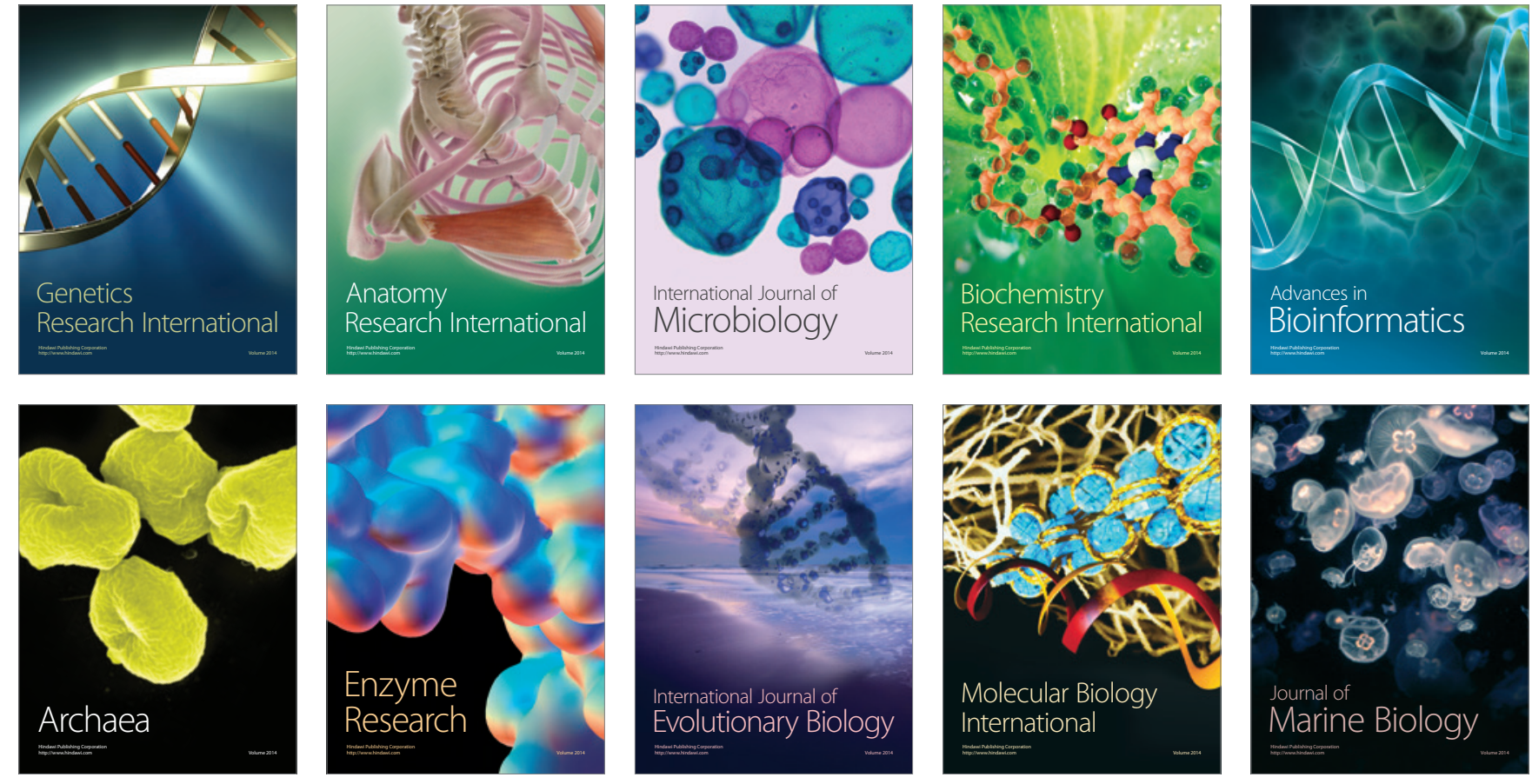